\title{
Ultrasonic Method for Evaluation of Annular Seals for Wells and Instrument Holes
}

Nazli Yesiller; Tuncer B. Edil, and Craig H. Benson

\begin{abstract}
An ultrasonic testing method employing the pulse-echo inspection technique was developed to assess the integrity of annular seals surrounding casings (i.e.. instrument tubes or well casings). This nondestructive testing method permits testing aseal from inside acasing without disturbing the casing, seal. or formation. Seals constructed with cement-based and bentonite-based sealants surrounding various Types and sizes of casings can be evaluated using the method. An evaluation is conducted by sending and receiving ultrasonic waves using a single piezoelectric transducer and commercially available hardware (a pulser receiver and a waveform analyur). A probe was designed and constructed for downhole testing. Differences in The ultrasonic responses of the malerials in contact with a casing are: analyzed to determine the presence of different materials (seal or defects filled with air or water in a seal) outside a casing,
\end{abstract}

Drilling boreholes is common practice in many disciplines rang. ing ftom geotechnical investigations to mine exploration, Often a pipe is inserted into a drilled hole such as inclinometer or piezometer tubes (in instrument holes) and well casings (in water supply or monitoring wells). These pipes will be referred to as "casings" in this paper.

When a casing is placed in a borehole, an annular space is created between the casing and tile surrounding soil. If not properly sealed, this annular space can be a potential path for transport of contaminants in the subsurface environment Cross contamination due to commingling of clean and contaminated groundwater can occur. A poor annular seal can also result in the loss of groundwater. Thus, proper installation and management of casings is necessary to protect tile subsurface environment. Furthermore, a properly placed seal also protects The casing against corrosion and chemical degradation (Nielsen and Schalla 1991; Landry 1992).

In this paper, a downhole ultrasonic method is described that can be used to assess the nature of materials (seal or defects filled with air or water) in contact with casings placed in boreholes. The ulrrasonic evaluation is a simple, yet sensitive testing method to assess seals without disturbing the casing, seal, or formation. The method can be used in casings made of metal or plastic. Seals constructed with cemenl and bentonite can be tested.

Existing Seal Evaluation Methods 
The most common methods used for in situ evaluation of seals around casings are: water level monitoring, pressure testing, and cement logging (Driscoll 1986). These methods are used primarily for water supply or oil wells having large-diameter casings. They are less frequently used for instrument holes or monitoring wells having small-diameter casings. A summary of existing in situ seal evaluation methods and their advantages and disadvantages is presented in Table I.

Level monitoring involves moniloring changes in the level of water or drilling fluid in the casing. If the seal is intact, virtually no change in liquid level is expected. This method requires simple instrumentation and can be conducted repeatedly after seal placement to monilor the performance of the seal in time. However, the fluid level in the casing is a crude indication of the quality of the seal. The fluid level is not affected unless the defects in the seal are hydraulically connected to the bottom of the casing or to leaky connections. Also, arches formed in the seal cannot be detected and, if poor performance is detected, the location of the defect cannot be identified. Leaks at the bottom or top of the casing can also be misinterpreted as a defective seal.

Pressure testing is used where the subsurface is primarily rock. This method can be used only 10 evaluate cement seals. The casing is pressurized under a pressure of $69 \mathrm{kPa}$ for at least $1 \mathrm{~h}$ after the cement has cured. If the cement seal is intact, virtually no drop in pressure due to leaks occurs over time. Pressurizing the casing can be conducted any time after curing of a cemenl seal, which allows monitoring of the seal over time. However, when soft formations exist around tile casing, pressure changes do not necessarily reflect the integrity of a seal. The surrounding formations can be compressed, and tile pressure drop can be misinterpreted as a defective seal.

Cement logging is a nondestructive testing method that has been used in tile oil and gas industries. Cement logs are designed to evaluate tile inTegrity of cement seals around steel oil and gas pipes using sound waves (Schlumberger 1981, 1989). Recenl appli· cations include evaluation of cement seals around waste disposal and deep water wells (Driscoll 1986; Landry 1992). Most cement logs supply information about the integrity of a seal, as well asinfonnation regarding the casing and the subsulface. Several cement logging tools arc available that fit into different diameter casings. Location of defects between a seal and casing, between a seal and formation, and location of channels in a seal can be determined. In addition, cement logging can be conducted in a casing at different times to monitor the seal over time.

The main disadvantage of cement logging is the high cost associated with testing. Logging services are provided by a limited number of companies using patented equipment and specially trained personnel. Data acquisition and analysis aR complicated. In addition, only steel casings and cement-based seals are evaluated with these tools. 
Two other less frequently used methods for evaluating cement seals are temperature logging and radioactive logging (Driscoll 1986). Temperature logs are conducted within 12 to $24 \mathrm{~h}$ after seal placement. The casing is filled with water, and the heat produced during curing of the cement is monitored by measuring the temperature of water inside the casing. The amount of heat produced is compared to that generated by a cenain mass of cement in a laboratory or field model. A lower temperature in the casing than the pre-determined value from the model is indicative of a defective seal.

In radioactive logging, a radioactive tracer is mixed into the cement sealant prior to placement. Radioactivity is monitored to verify the position of the cemenl after the seal is placed in the annular space. This method is expensive and requires special procedures for handling of radioactive material. In addition, the radioactive material affects the natural radioactivity of earth. This can result in misinterpretations of nuclear geophysical studies conducted in the vicinity of the casing.

A variety of materials are used for seals (bentonite. cement. etc.) and casings (steel, PVC. etc.) in geotechnical and geoenvironmental applications (Lutenegger and DeGroot 1994). On the basis of the limitations of the existing methods, there is need for a simple, yet sensitive testing method to evaluate this wide range of commonly used materials. This method should also allow for repetitive tests after seal placement to monitor the performance of a seal over time. For this reason, a nondestructive testing method that uses ultrasonic principles was developed.

\section{Apparatus}

In this project, methods used for ultrasonic nondeslructive testing of materials were adapted for evaluating the integrity of sealsaround a casing. The pulse-echo inspection technique was used. A single transducer was used to send and receive ultrasonic waves into the casing and seal. Reflections generated as the waves pass into the casing and seal were analyzed to investigate the integrity of a seal.

\section{Electronic Equipment}

The eletronic equipment used for seal evaluation consists of three units: (I) a transducer. (2) a pulser-receiver, and (3) a waveform analyzer (Fig. I). Two different piezoelectric transducelS were used to transmit and receive ultrasonic waves. A Panametrics V106 Series22.25-MHz-ccnter-frequency broadband (94.1\% bandwidth) transducer was used for tests with steel casings. A Panameuics AI03S Series I.Q.MHzcenter-frequency narrowband ( $40 \%$ bandwidth) transducer was used for tests with PVC casings. 
The transducer is actuated by a pulser-receiver (Panametrics Ultrasonic PulserReceiver Model 5055PR), which is connected to a waveform analyzer (Ana logic Data Precision Universal Wavefonn Analyzer with Data 6000 Mainframe and Model 620-1 PlugIn) for digitization of data (Fig. I). The IQ.MHz-bandwidth broadband pulser-receiver has an adjustable repetition rate in the range of $100 \mathrm{~Hz}$ to $2 \mathrm{kHz}$, with a i-v output for synchronous triggering of the wavefonn analyzer during data acquisition. The Plug-In 6201 provides for two-channel data acquisition with frequencies up to $100 \mathrm{MHz}$.

The electronic components are connected with RG 53-BNC cables. A BNC+lomicrodot adapter is used to connect the RG .58BNC cable to the transducer. The adapter is a 5-mm-long rigid connector wilh a diameter slightly larger than the diameter of a BNC cable. The procedures for setup and use of the electronic equipment are described in detail by Yesiller (1994).

\section{Water Supply Syslem}

Presence of water is required in front of the transducer $10 \mathrm{aCI}$ as a couplant for lransmission of ultrasonic waves. If the casing is filled with waler, measurements can be conducted immediately. However, if the casing is not filled with water, a system to supply water in front of the transducer is used (Fig. 2). A soft rubber ball is lowered inside the casing below the transducer and pressurized at the desired depth. The innated ball plugs the casing and allows for the panion of the casing above the rubber ball to be tillcd with water (Fig. 2). After data acquisition is complete, the rubber ball is collapsed by releasing lhe pressure. Rubber balls of various diameters are available for use in different diameter casings.

Probe

The probe is a cylindrical unit constructed from Delrin ${ }^{\circledR}$ that houses the transducer. Delrin, a plastic, was used because it is easily machined and has a low coefficient of friction, which pennits the piston used to position the probe to slide easily within its cylinder while maintaining an adequate seal. A thin brass disk is attached to the bottom of the probe as a counterweight (Fig. 3).

The transducer is placed inside a cylindrical space in the probe (Fig. 3). A solid piston that can move in and out of the probe is used to fix the probe at a certain location inside a casing. The probe is designed to fit into casing having a diameter of $50 \mathrm{~mm}$. However, piston of various lengths can be placed in the probe when using it in largerdiameter casings. 
The probe is deployed in a casing using a set of rigid aluminum rods. A $240-\mathrm{kPa}$ pressure source (compressor or bottled compressed air), plastic tubing, a cap that fits on top of a casing, and an inflatable rubber ball (when the casing is not full of water) are used.

The probe is lowered inside the casing via the rods to the desired depth of measurement. The probe is pressed against the casing by applying a pressure of $240 \mathrm{kPa}$ to the piston. A vertical cross section showing the pressurized probe in lhe casing is shown in Fig. 4. In this configuration, the face of the transducer is orthogonal to the casing wall, which pennits the maximum amount of ultrasonic energy to be transmitted into the casing (Fig. 4). Also, a fixed lhickness of water $(12.7 \mathrm{~mm})$ is maintained in front of the transducer to act as a couplant (Fig. 4). Pressurizing the probe against the casing wall and maintaining a fixed thickness of water in front of the transducer eliminates the need for centralizing the probe, which is a significant concern in some commercially available cement evaluation tools (Schlumberger 1981; Bigelow 1985).

A test is conducted at lhe measurement location after the probe has been pressed against the casing wall. After data collection at a given location, the probe is retracted by releasing the pressure. The probe is then lowered to the next measurement location or rotated horizontally to conduct measurements along different directions.

\section{Data Acquisition and Analysis}

\section{Principles}

In the ultrasonic method, the seal around a casing is conceptualized as a threelayered system (Fig. 5). Ultrasonic waves sent by the transducer travel through the coupling medium (water), the casing, and the seal. When the incident wave (i.e., I) encounters the boundaries between layers, its energy is distributed between reflected (i.e., RI• R2) and transmitted waves (i.e., T I, T2). Reflections from the boundary between the casing and seal are received by the same transducer. Differences in the acoustic properties of media present behind the casing cause differences in the reflected wave energies. Analysis of these reflected waves indicates the presence of different media (seal or defects filled with air or water in a seal) behind a casing.

Reflected wave sequence generated as a re ult of a ingle excitation of the transducer are illustrated in Fig. 6. The amplitude of reflections from the water-casing and casingbacking interfaces are proportional to the length of the arrows in Fig. 6. The incident sound impulse from the transducer travels through the coupling medium (water) and strikes the inner surface of the casing. Some energy is reflected back to the transducer, and some undergoes multiple reflections within the casing depending on the acoustic properties of the casing and the backing material (e.g., sealant, air, water, or formation). The quality of 
the bond between the casing and the seal is assessed by evaluating the amount of energy reflected from the boundary between the casing and the seal.

The amount of energy reflected and transmitted is determined by the contrast in acoustic impedance (velocity of sound in a material times the density of the material) between the casing and backing material. Acoustic properties of the common casing and seal materials encountered in sealing applications are listed in Table 2 . Because the acoustic impedance of water and the casing are essentially constant, the signal inside a casing decays at a rate that depends on the acou tic impedance of the material behind the casing. In a typical waveform, a high-amplitude initial reflection from the water-casing interface is followed by multiple reflections from the casing-seal interface that decay exponentially (Fig. 6).

The waveforms shown in Fig. 7 are typical of waveform obtained using steel casings. When there is no backing (air), the initial high-amplitude reflection from the water-casing interface i followed by multiple sharp reflections from thecasing-airinterface. The low acoustic impedance of air, relative to the acoustic impedance of the steel casing (Table 2), results in low transmission of energy into the air. Most of the energy in the incident pulse that strikes the casing-air interface is contained within the casing and thus generates sharp reflections as shown in Fig. $7 a$.

When a sealant such as neat cement is present behind the steel casing, the initial high-amplitude reflection from the water-casing interface is followed by low-amplitude reflections from the casingcement interface that decay quickly. The acoustic impedance of neat cement is significantJy higher than that of air (Table 2). Therefore, more energy is transmitted into the cement relative to the transmission into air. As a result, less energy is contained in the casing and reflections with lower amplitude are generated (Fig. 7b). This difference in the waveforms is used to discriminate between intact and defective seals.

\section{Data Acquisition}

A measure of energy, $E N G$, i used to quantify characteri tics of the reflections from the casing-seal interface. Different valuesfor ENG are obtained depending on whether the seal is intact or defective. $E N G$ is the area under the amplitude-time plot over a specified time interval. It is calculated as the sum of the squares of the amplitudes (voltage) with respect to a designated reference value multiplied by the period of the waveform. It is an integral measure of both amplitude and time (Fig. 8). The equation for ENG is:

$$
\left.\begin{array}{ll}
2 & 2
\end{array}\right]
$$


where $N$ is the total number of points in the waveform, $v i$ is the amplitude of point " $t$ ' in volts, $V_{\text {ref }}$ is a designated reference amplilude (volts), and tit is the time difference (period) belween consecutive points in the waveform ( $\mu$ s) (Fig. 8). The presence of different materials behind the casing causes changes in Ihe ampliludes of reflections from the casing-seal interface and thus changes in $E N G$. Therefore, $E N G$ is used to evaluate the pans of Ihe waveforms lying belween arrows in Fig. 7.

Depth and $E N G$ are recorded at each measurement location along the length of a casing. The wavefonn analyzer is programmed to take 16 measurements of $E N G$ al each test point using a procedure described in Yesiller (1994). If the standard devialion of these 16 measurements is below 5\%, the mean of the measurements is recorded as ENG for that panicular depth. If the slandard deviation is above $5 \%$, measurements are repeated until the Slandard deviation drops below 5\%.

\section{Data Analysis}

The $E N G$ recorded for each measurement depth are statistically analyzed to assess the integrity of seals. Results of the slatistical analysis are shown on a graph of $E N G$ versus location along Ihe casing. A low value of $E N G$ is indicalive of an "intact" seal, whereas a high value for $E N G$ indicales a "defective" seal.

To discriminate quantilatively between an "inlact" seal and a "defective" seal, a measured profile of $E N G$ is compared 10 the profile expected for a defeclive seal (Fig. 9). A seal that is in full contact with the casing is an "intact" seal, whereas defects consisling of water or air around the casing correspond 10 a "defective" seal. A t-lest is conducted to determine the difference between data from a sealed casing and data from water backing or no backing (air) around the same casing. A t-test consists of computing the difference belween two sample means and Ihen determining whether this difference is significanl al a specified significance level Q (Cheeney 1983). If the difference is significanl, Ihe computed I-slatistic $(t)$ is higher than a critical $t(a)$ at the specified significance level. This indicates that Ihe two compared values do not belong to the same population.

$E N G$ for air and water around a casing are needed to provide a frame of reference for quantilative analysis of the condition of a seal around Ihe casing. ENG for air backing can be obtained immediately from tests that are conducted on the seclion of a casing above the ground surface. However, a water-filled annular space surrounding the casing above ground level is required for lests with water backing. Such an annular space can be created using a section of pipe larger in diameter than the casing (Yesiller 1994).

Results for air, water, and the in situ seal are shown on a graph of $E N G$ versus depth (Fig. 9). Data from the sealed casing are statistically compared to data from the initial water 
and air tests to detennine the condition of the seal. The comparison to water is conducted first. A I-slatistic is computed using each data point (i.e., al a given depth) for Ihe sealed casing and the sample mean and the sample slandard deviation for the water backing test. A significance level of 0.05 corresponding to a $95 \%$ confidence interval is used. Locations where the difference between the data poinl and mean for waler is significant $\left(t>t_{e r}\right)$ correspond to localions where the seal is intact (Fig. 9). When the difference between the dam point and mean for water is not significant, the seal is defective (Fig. 9). A negative $t$ corresponds 10 an $E N G$ grealer than that for water. Therefore, a negative / indicates a defective seal regardless of ilS significance. A similar evaluation is conducled to compare the data for the sealed casing 10 the data for a casing having air as the backing. Results from the Hests are listed in tabular form. The condilion of the seat is then shown on the graph of $E N G$ versus depth. The profiles for the sealed casing, water backing, and no backing (air) arc shown on the same graph, with the seal being deemed inlact or defective using results from the l-tests (Fig. 9).

\section{Testing Program and Results}

\section{Laboratory Tests}

Model boreholes were conslructed in the laboratory to evaluale the effectiveness of the ultrasonic method in a cylindrical arrangement. A section of PVC pipe was used to create an annular space surrounding a 5 -cm.diameter casing made of slainless sleel or PVC (Fig. 10). The annular space was filled with different sealants and/or fonnalion materials. Tests were conducted for intact seals (benlonite and neat cement), materials representative of defects (air and water), formation materials (sand), and seals containing defects.

\section{Microannulus Defect}

Initially, air and water were tested in the annular space of a 380-mm-diameter borehole model (Fig. 1Oa). A neat-cement seal was then placed in the annular space of this model the seal was prepared using a ratio of $2 \cdot \mathrm{kg}$ Type I Portland cement to $1 \mathrm{~L}$ of water. This recipe for neat cement is commonly used in field applications (Strata Engineering Corporation 1991; Edil et al. 1992; Wisconsin Department of Transportation 1994). The casing was a Sch. 40 stainless steel pipe (50-mm nominal diameter), which is commonly used for constructing monitoring wells (Nielsen and Schalla 1991).

Measurements ofENG were conducted at 20-mm intervals along the length of the casing after placement of the neat cement. Results of the t-tests conducted on data collected at different times are listed in Table 3. Fresh cement (2-h test) produced $E N G$ lower than that for water or air, indicating full contact between the seal and the casing (Fig. 1Ob), that 
is, the average $E N G$ obtained at each point was statistically different from the $E N G$ for water and air. However, as the cement cured. The ENG increased at the base and top of the casing, indicating a defect was developing (Fig. IOe). The defect was a separation between the seal and casing, which is referred to as a "microannulus" (a small gap between the casing and cement seal) in the oil and gas industries (Fenl et al. 1974; Schlumberger 1981, 1993; Bigelow 1985). At the end of three days, no significant difference existed between the measured $E N G$ and those for air (Table 3), indicating that the entire casing lost contact wilh the cement (Fig. 10d). Subsequent examination showed that an air-filled microannulus developed along the entire casing-cement seal interface (Yesiller 1994).

\section{Arching or Cave-In Defect}

A specimen was also tested that had a benlOnite seal with a single large defect (Fig. lla) simUlating caved-in sand fonnalion material. The specimen was prepared by first filling the bottom $0.25 \mathrm{~m}$ of the model borehole with a bentonite seal. The bentonite seal was prepared with granular bentonite, a retarding agent, and water. The resulting seal was composed of $22.6 \%$ benlonite (Benseal ${ }^{\circledR}$ ), $2 \%$ retarding agent (Aqua-Grout ${ }^{\circledR}$ ), and $75.4 \%$ water by weight (recipe from 8aroid Drilling Fluids Inc. 1994). A 0.15 $\mathrm{m}$-thick layer of sand was then placed over the bentonite layer to imulate a caved-in defect. An additional $0.20 \mathrm{~m}$ of bentonite was placed on top of the sand. Result of t-test conducted on the data from ultrasonic tests is listed in Table 4. u>w ENG were obtained at locations where the casing was surrounded by bentonite; the $E N G$ for bentonite were significantly different from the $E N G$ for air (Table 4), indicating full contact between the seal and the casing (Fig. lib). However, the $E N G$ increased harply to values similar to that for air at locations where the casing was surrounded by sand (Fig. lI I b). The t-tests showed that the difference between the $E N G$ for and and air was not tatistically significant (fable 4), indicating the presence of a defect.

\section{Local Defects}

A second specimen with a bentonite seal was prepared in a $100 \mathrm{~mm}$-diameter model borehole with multiple local defects (Fig. 12a). The bentonite seal was similar in composition to the cavein bentonite seal.

Defects were constructed using 40-mm-wide geotextile strips attached to the casing at three different depths. The geotextiJe strips were cut to various lengths and wrapped around the pipe at predetermined locations. The top defect was con tructed by placing the geotextile strip around one fourth $\left(90^{\circ}\right)$ of the perimeter of the casing. The middle defect was constructed by placing the strip around half $\left(180^{\circ}\right)$ the perimeter of the ca ing. The bottom defect was constructed by wrapping the geotextile strip around the entire $\left(360^{\circ}\right)$ perimeter of the casing. 
Measurements were conducted at three different orientations within the casing by rotating the probe (Fig. $12 \mathrm{~b}$ ). The resulting $E N G$ were compared to $E N G$ obtained from tests conducted with air backing around the same casing. All of the defects were detected in the first test $\left(0^{\circ}\right.$ orientation). When the probe was rotated $120^{\circ}$ horizontally, the top defect could no longer be detected. Finally, when the probe was rotated $240^{\circ}$, only the bottom defect could be detected. These results agreed precisely with the placement of the defects.

\section{Field Tests}

Field test were conducted in four boreholes haVing different sealing conditions. Bentonite and neat cement were used for seals, and defects were introduced using sand. The boreholes were $152 \mathrm{~mm}$ in diameter and were installed using a hollow stem auger. Casings placed in the boreholes were 50-mm-diameter Sch. 40 steel pipes. ENG for water backing and air backing were determined using a 0.3 to I-m section of the casings above ground level. Tests were conducted at different times after placement of seals. Similar results were obtained for tests on all four boreholes (Yesiller 1994).

Results from the test conducted on a bentonite seal containing a sand defect layer are shown in Fig. 13. ENG for air and water backing (reference measurement for comparison) obtained from the section of the pipe above ground level are also shown in Fig. 13, The casing was $3 \mathrm{~m}$ long, $2.7 \mathrm{~m}$ being below ground and the remaining $0 \mathrm{~J} \mathrm{~m}$ above ground. The stratigraphy of the site consisted of a 0.6 -m-thick layer of top soil and an underlying layer of silty sand. Groundwater was not present.

A bentonite seal was prepared with Pure Gold ${ }^{\circledR}$ medium bentonite chips and water using recipes and procedure employed by the Wisconsin Department of Tran portation (1994). Pure Gold medium chips are 9.5-mm-diameter bentonite chips manufactured by Colloid Environmental Technologies Company (CETCO). The recipe resulted in a seal composed of $54.5 \%$ bentonite and $45.5 \%$ water, by weight.

Bentonite seals were placed in me annular space by filling the space with water to a specified depth and then dropping bentonite chips into the water. The sand defect between the bentonite layers was placed in the annular space by dropping the sand from the ground surface. The seals and defects placed in the borehole, from top to bottom, consisted of a 0.9$\mathrm{m}$-thick bentonite seal at the surface, a 0.8 -m-thick sand layer simulating a defect, and finally another bentonite seal $1.0 \mathrm{~m}$ thick at the bottom (pig. 13a).

Results of a test conducted one day after construction are hown in Fig. $13 b$ with data collected from te $t$ conducted on the section of the pipe above the ground surface that defined the $E N G$ for air and water (reference measurements). The ultrasonic responses obtained from the eal and defect layers were different. Near the top of the upper bentonite 
layer, $E N G$ was high, indicating the presence of a defective seal (e.g., $\mathrm{t}$ (seal-air) $=-0.09<t a$ $=2.11$ at 0 . I $\mathrm{m}$ depth). In fact, desiccation and cracking of the bentonHe seal was visually observed at the ground surface. In contrast, $E N G$ was low for the lower portion of this layer, indicating the presence of an intact seal (e.g., $\mathrm{t}$ (seal-water) $==4.59>t a==2.11$; $\mathrm{t}$ (seal-air) $=6.87>t c r=2.11$ at $0.6 \mathrm{~m}$ depth). $E N G$ for the lower bentonite seal was also low (except for one location at $2 . \mathrm{I} \mathrm{m}$ depth), indicating the presence of an intact seal (e.g., $t=$ 3.96 (seal_water) $>t c r==2.11$; $\mathrm{t}$ (seal-air) $=6.60>t^{\prime \prime} r==2$. I I at $2.5 \mathrm{~m}$ depth).

$E N G$ for the sand layer was close to that of water at all locations one day after placement, even though dry sand was placed in the borehole as the defect layer (e.g., $t=$ 0.67 (seal-water) $<t a==2.11$ at $1 \mathrm{~m}$ depth). The writers hypothesized that water used to hydrate the bentonite seal above the sand layer seeped into the sand. Results of tests conducted in thi borehole days later confirmed this hypothesis (e.g., $t=0.27$ (seal-air) $<t a=$ 2.11 at $1.1 \mathrm{~m}$ depth at the end of seven days, YesiUer 1994).

\section{Summary}

An ultrasonic nondestructive testing method employing the pulse-echo inspection technique was developed to evaluate the integrity of annular seals surrounding casings (instrument tubes and well casings) in boreholes. The test equipment consists of readily available and non-proprietary components. The testing and analysis procedures are reasonably simple to use. A single piezoelectric transducer along with commercially available hardware (a pulser receiver and a waveform analyzer) are used for data acquisition and analysis.

A probe that houses the transducer was designed and constructed for downhole testing. A data acquisition and analysis method was developed for seal evaluation using the probe. The method was initially developed and evaluated in the laboratory. Its effectiveness was then evaluated in the field. The ultrasonic method is effective for detecting the presence of seals consisting of bentonite and neat cement and the presence of defects composed of air, water, or coarse-grained formation materials such as sand that are in contact with a casing. However, in its current stage of development, the method cannot be used to detect the presence of defects that are not in contact with a casing. Separations on the order of micrometers between the seal and the casing can be detected and defects having an area as small as the area of the face of the transducer $(250 \mathrm{~mm} 2)$ can be located. Measurements can be conducted along any direction in a casing by rotating the probe horizontally in the casing.

Seals around steel and PVC casings can be evaluated. It is relatively imple to modify the algorithm to test other metallic or plastic casings. The probe can be used in its current configuration for casings with diameters ranging from 50 to $100 \mathrm{~mm}$ (using different 
pistons), but can also be easily modified to fit into casings having smaller or larger diameters.

\section{Acknowledgements}

Financial support for this study was provided by Federal Highway Administration (FHWA) and the University of Wisconsin System Groundwater Research Advisory Council (GRAC). The findings and opinions expressed in this paper are solely of the authors and are not necessarily consistent with the policies or opinions of FHWA or GRAC. Dr. SelcukSancar provided technical expertise relating to the ultrasonic method and general guidance for the project. Appreciation is also expressed to Mr. Xiaodong Wang, who assisted in construction of the test apparatus.

\section{References}

Baroid Drilling Fluids Inc., 1994. Groundwater Monitoring Products, Houston TX.

Bigelow, E. L., 1985, "A Practical Approach to the Interpretation of Cement Bond Logs," Journal of Petroleum Engineering. Vol. 37, July, pp. 1285-1294.

Bray. D. E. and Stanley. R. K.. 1989. Nondestructive Evaluation: AToolfor Design. Manufacturing. and Service, McGraw-Hili, Inc., New York, NY.

Cheeney, R. E, 1983, Statistical Methods in Geology, George Allen \& Unwin Publishers LId., London. UK.

Driscoll. F., 1986 Groulldwater and Wells. Johnson Division, UOP Inc.. St. Paul, M .

Edil, T. B., Chang, M. K., Lan, L. T., and Riewe, T. W., 1992, "Sealing Characteristics of Selected Grouts for Water Wells." Ground Water. Vol. 30. No.3, pp. 351-361.

Ensminger, D., 1988, Ultrasonics: Fundamentals. Technology, Applica· tions, Marcel Dekker, Inc. $•$ New York, NY.

Fertl, W. H., Pilkington P. E., and Scan. 1. B., 1974. "A Look at Cement Bond Logs," Journal of Petroleum Engineering, Vol. 26 June, pp. 607-617.

Landry, P. G., 1992, "The Applications or Acoustic Cement Bond Logging to Wc:fl Casina Evaluation and Remcdiuion Programs,Proceedings, Sixth National Outdool- Action Conrerence on Aquirer Restoration, Ground Wuer Monitoring and Geophysical Methods., National Groundwater Association, Dublin. OH, pp. 716-728. 
Lutenegger, A. J. and DeGrool, D. J., 1993. "Hydrologic Properties of Containment Transport Barriers as Borehole Sealants" Hydraulic Conductivity and Waste Containment Transport in Soils. ASTM TP 1142, DE Daniel and SJ Trautwein, EDS, American Society for Testing and Materials, Weat Conshohocken, PA

Nielsen. D. M. and Schalla, R.. 1991. Design and Installation of Ground-Water Monitoring Wells, Practical Handbook of Ground Water Monitoring, DM Nielsen, Ed, Lewis Publishers Inc. MI

Sanear, S. 1992, Interim Summary Report, Department of Civil Engineering, University of Isconsin on Verification Technique to Evaluate Integrity of Seals in Geotechnical Boreholes Project, Madison, WI

Schlumberger Inc., 1981. Cement Bond-Vaiability, Density Log, Houston, TX

Schlumberger Inc, 1989, Cement Evaluation Tool, Houston, TX

Strata Engineering Corporation, 1991, Quarterly Progress Report to the National Cooperative Highway Research Program on Project TRB 21-4 Sealing Geotechnica Explatory Holes to Protect the Subsurface Environment, Washington, DC

Yesiller, N.. 1994. Ultrasonic Evalualton of Cased Borehole Seals,Ph,D. thesis, University of Wisonsin-Madison. Department orCivil and Environmental Engineering, Madison. WI.

\begin{tabular}{|c|c|c|}
\hline Method & Advantages & Disadvantages \\
\hline Level monitoring & $\begin{array}{l}\text { Simple } \\
\text { Can be conducted repeatedly after seal placement }\end{array}$ & $\begin{array}{l}\text { Crude } \\
\text { Location of defects cannot be identified }\end{array}$ \\
\hline Pressure testing & Can be conducted repeatedly after seal placement & $\begin{array}{l}\text { Only cement seals in rock formations can be } \\
\text { tested } \\
\text { Location of defects cannot be identified }\end{array}$ \\
\hline Cement logging & $\begin{array}{l}\text { Both casing-seal and seal-formation bonds can be } \\
\text { evaluated } \\
\text { Exact location of defects can be identified } \\
\text { Can be conducted repeatedly after seal placement }\end{array}$ & $\begin{array}{l}\text { High cost } \\
\text { Services provided by a limited number of com- } \\
\text { panies using specialty equipment } \\
\text { Only cement seals around steel casings are } \\
\text { tested }\end{array}$ \\
\hline Temperature logging & Simple & $\begin{array}{l}\text { Only cement seals can be tested } \\
\text { Must be conducted within } 12-24 \text { hours after } \\
\text { placement of seal }\end{array}$ \\
\hline Radioactive logging & $\begin{array}{l}\text { Location of defects can be identified } \\
\text { Can be conducted repeatedly after seal placement }\end{array}$ & $\begin{array}{l}\text { High cost } \\
\text { Special procedures required for handling of } \\
\text { radioactive material }\end{array}$ \\
\hline
\end{tabular}


DISK DRIVE

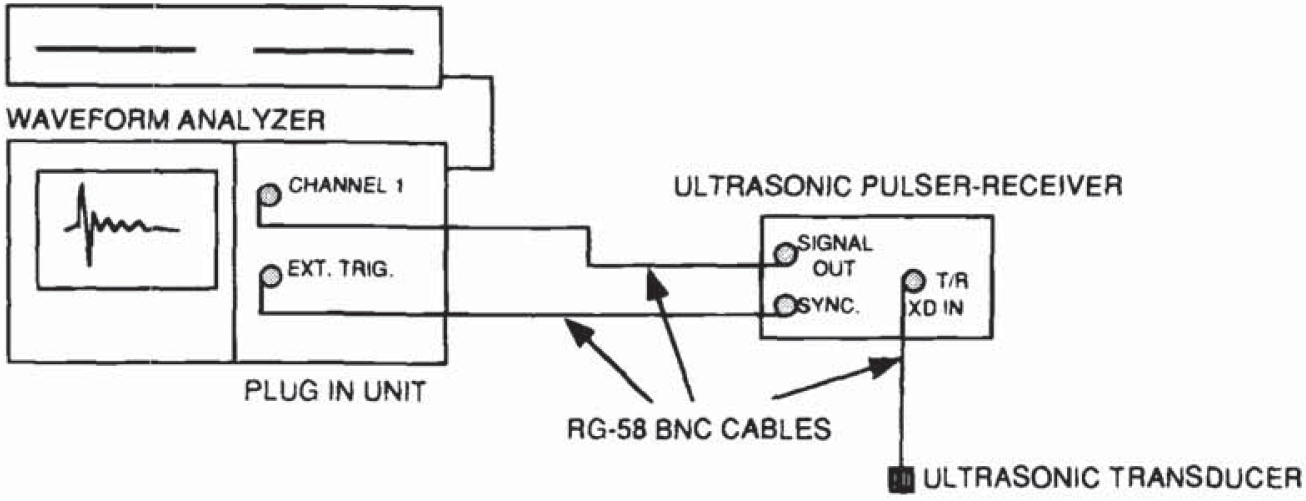

FIG. 1-Electronic equipment.

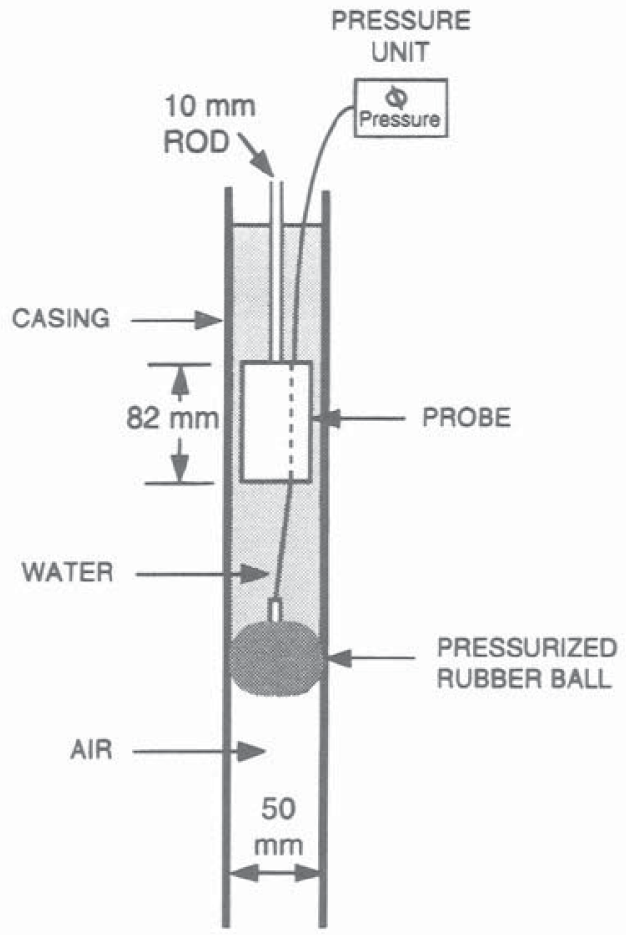

FIG. 2-Water supply system. 


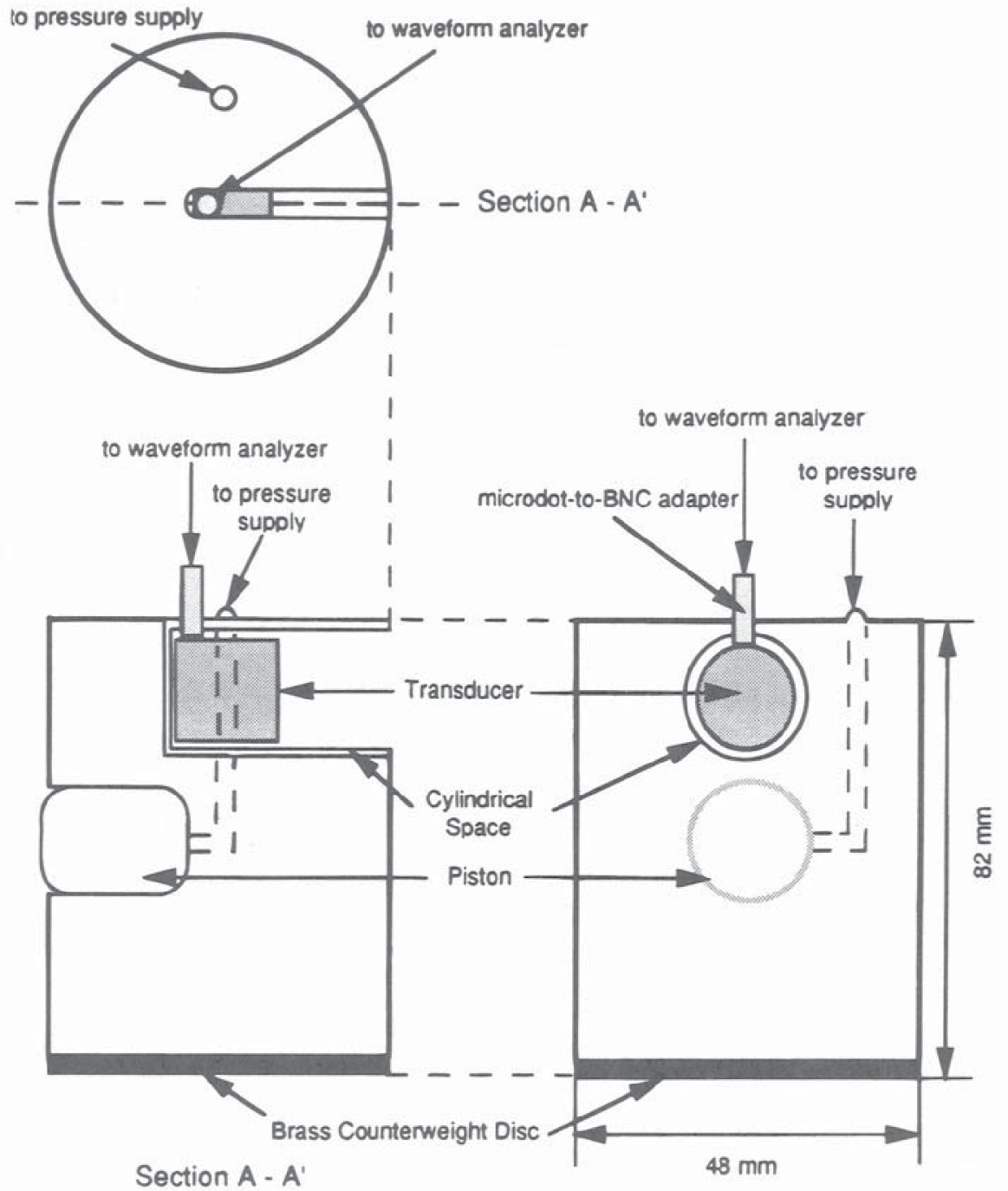

FIG. 3-Schematic of probe. 


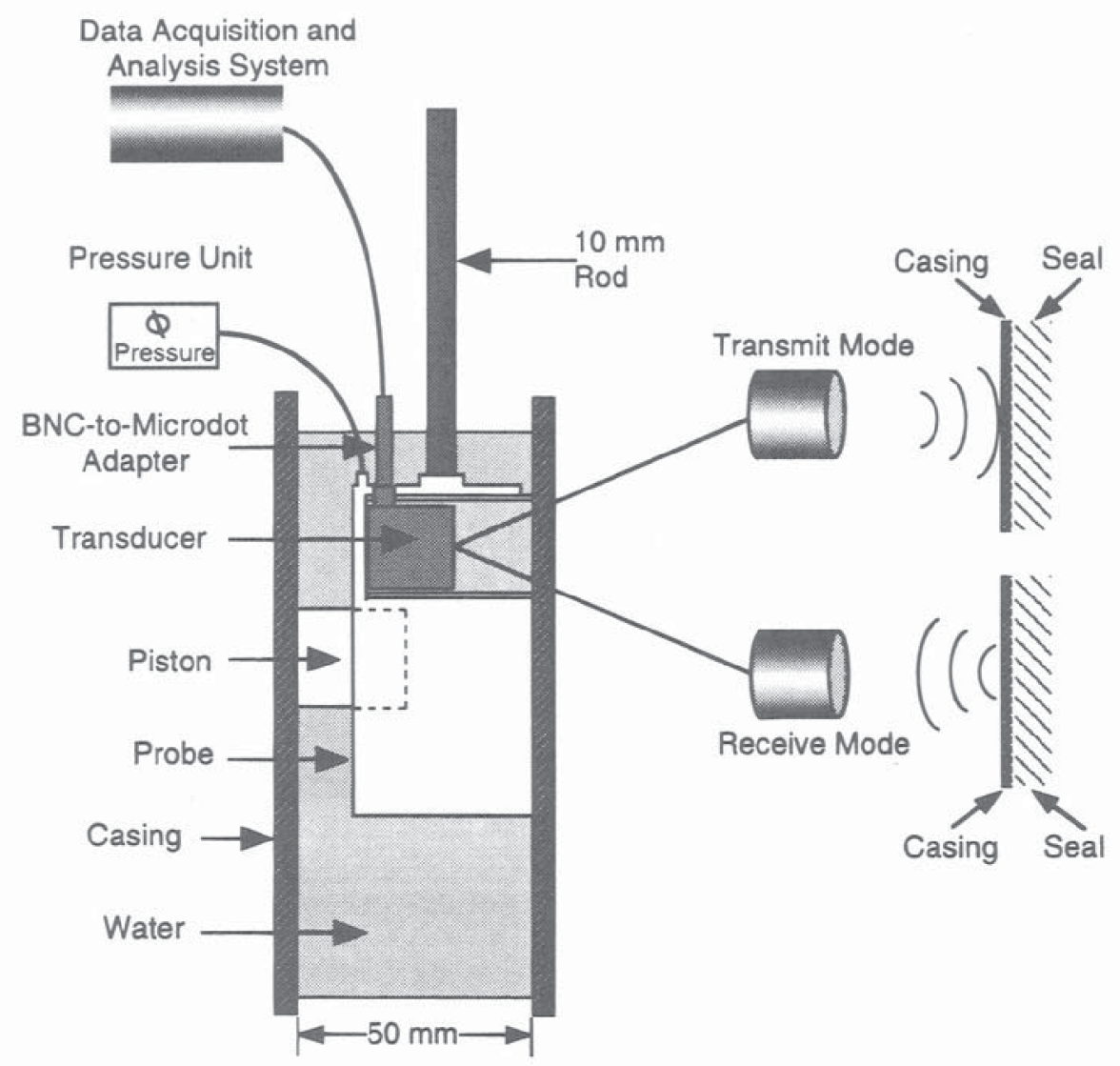

FIG. 4 Probe deployed in a casing. 


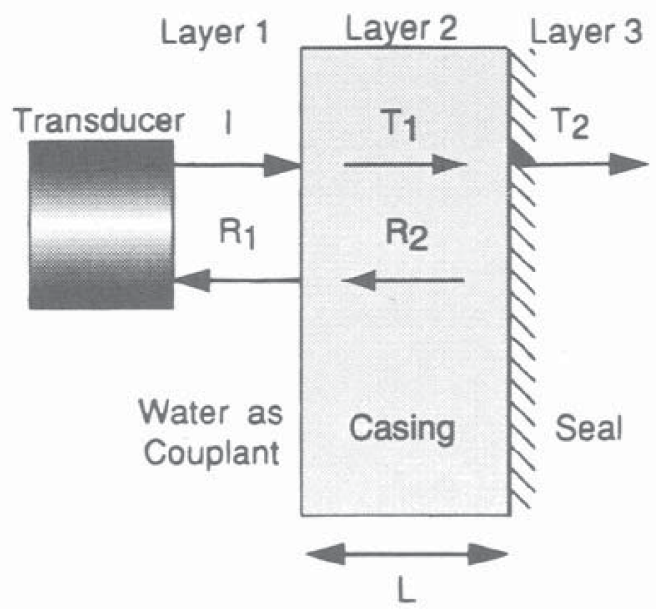

1 = Incident wave

$R_{1}=$ Wave reflected from the boundary between 1 and 2

$T_{1}=$ Wave transmitted to layer 2

$R_{2}=$ Wave reflected from the boundary between 2 and 3

$T_{2}=$ Wave transmitted to layer 3

FIG. 5-Three-layered system used in the tests.

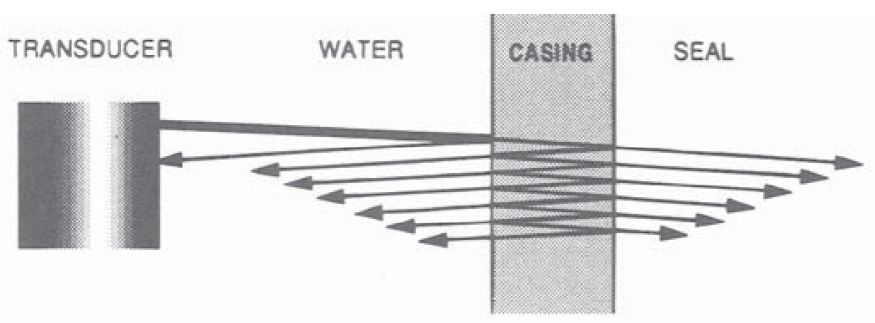

Incident impulse from the transducer

Multiple reflections generated by single excitation of the transducer

Note: Waves are actually normal to the interfaces, but are illustrated at an angle for clarity.

FIG. 6-Wave sequences generated in planar tests. 
TABLE 2-Acoustic properties of the materials used in this study.

\begin{tabular}{|c|c|c|c|}
\hline Material & $\begin{array}{c}\text { Density, } \rho \\
\left(10^{3}\right)\left(\mathrm{kg} / \mathrm{m}^{3}\right)\end{array}$ & $\begin{array}{l}\text { Velocity, } c \\
(\mathrm{~m} / \mathrm{s})\end{array}$ & $\begin{array}{c}\text { Impedance, } z=\rho x c \\
10^{6}\left(\mathrm{~kg} / \mathrm{m}^{2} \mathrm{~s}\right)\end{array}$ \\
\hline Steel $^{a}$ & 7.70 & 6100 & 47.0 \\
\hline Air (STP) ${ }^{b}$ & 0.00121 & 343 & $4.15 \times 10^{-4}$ \\
\hline Water (STP) ${ }^{b}$ & 0.998 & 1483 & 1.48 \\
\hline Dry sand (medium) ${ }^{c}$ & 1.61 & 1700 & 2.74 \\
\hline Bentonite $^{d}$ & $1.15-1.17$ & $2100-2700$ & $2.42-3.16$ \\
\hline Concrete $^{c}$ & 2.60 & 3100 & 8.10 \\
\hline $\begin{array}{l}\text { Plastic }^{b} \\
\quad \text { (simulating PVC) }\end{array}$ & 1.20 & 2680 & 3.2 \\
\hline
\end{tabular}

${ }^{a}$ Bray and Stanley (1989).

${ }^{b}$ Ensminger (1988).

'Sancar (1992).

${ }^{d}$ Measured in model borehole tests.

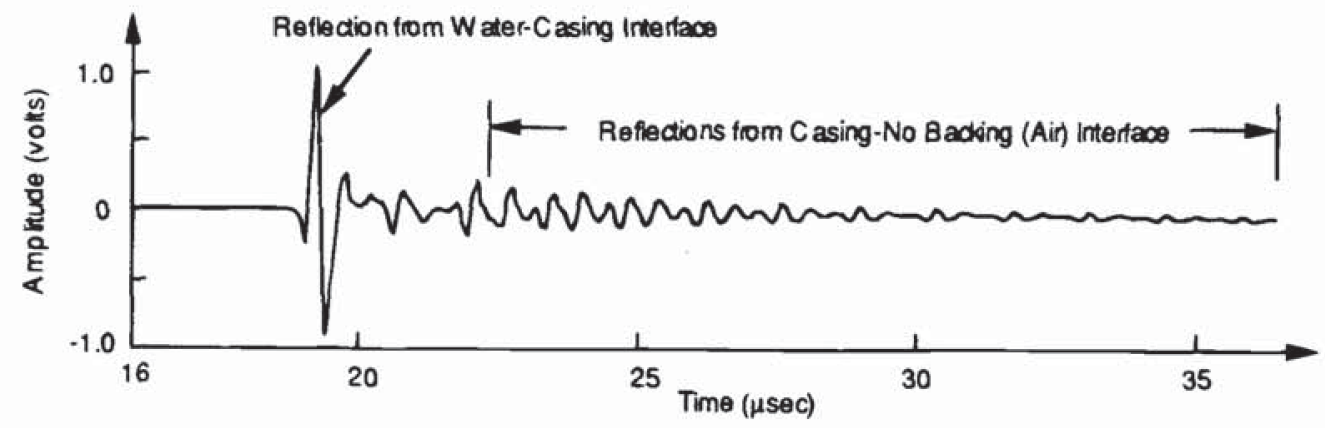

(a)

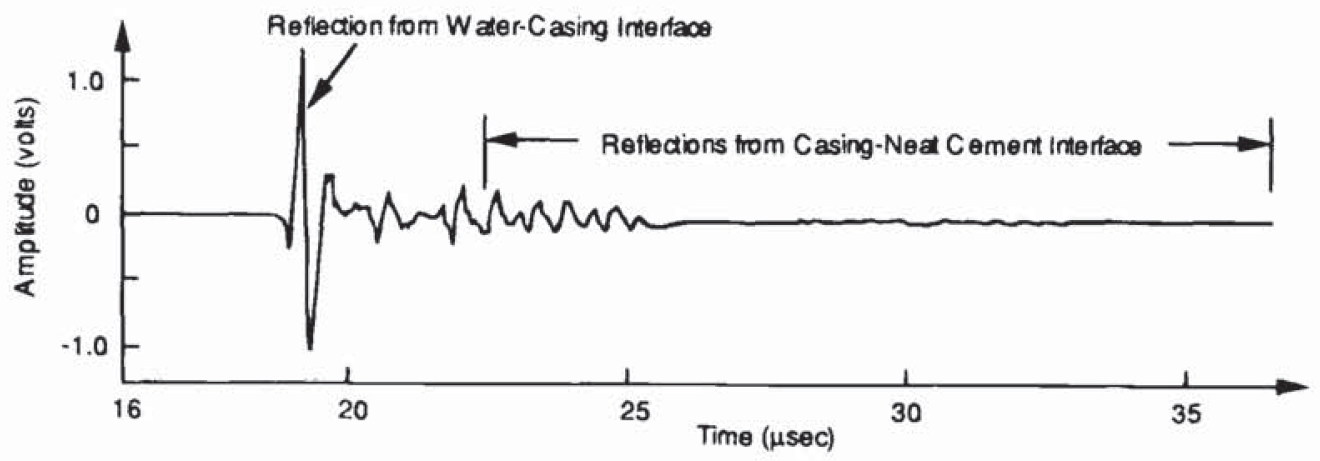

(b)

FIG. 7-Two typical waveforms obtained from tests with steel casings: (a) no backing (air) and (b) neat-cement backing. 


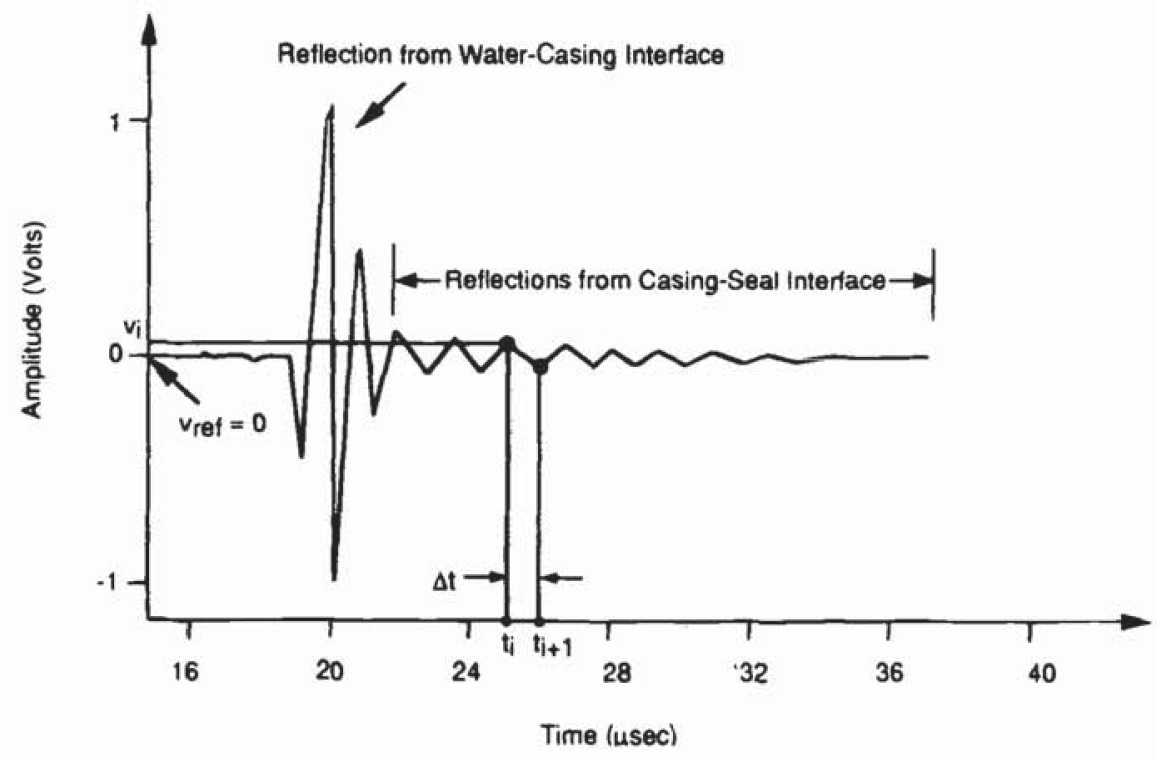

FIG. 8-A typical waveform.
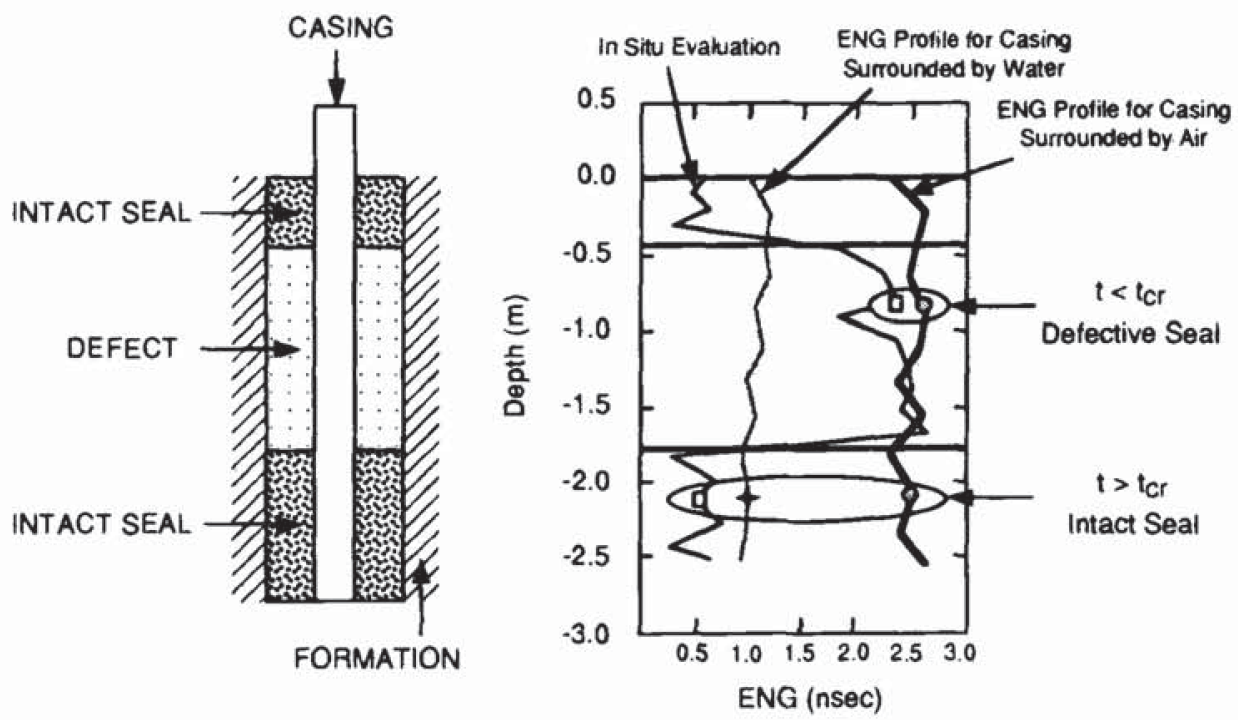

FIG. 9-Example of data analysis. 


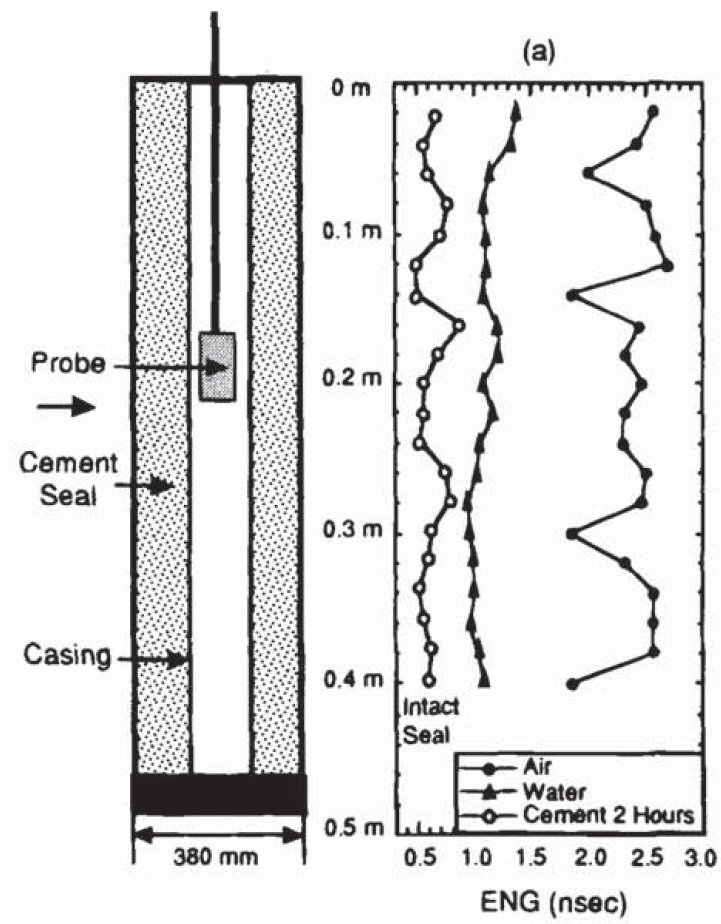

(b)

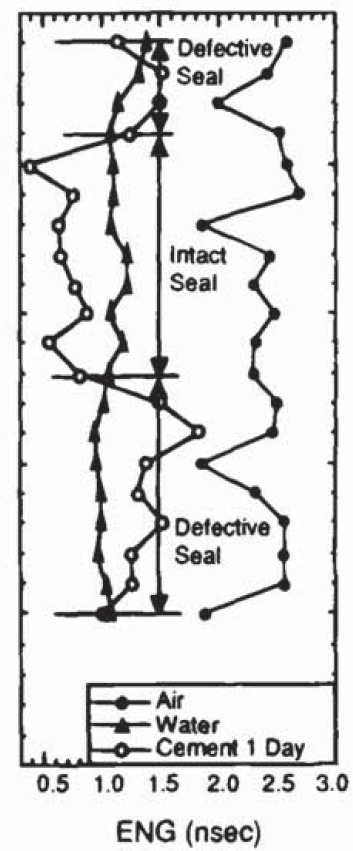

(c)

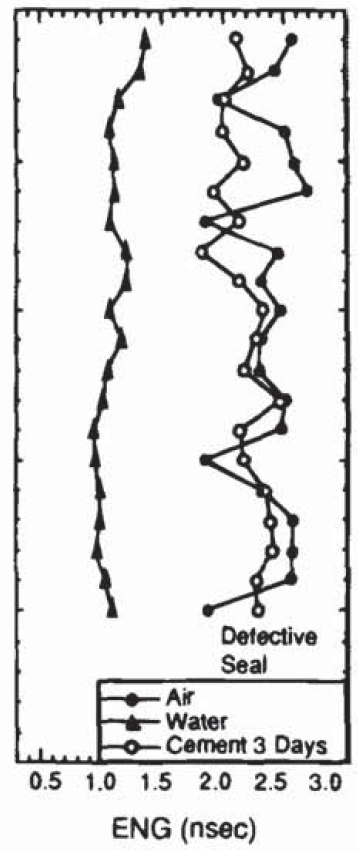

FIG. 10-Results of tests with air, water, and neat cement in the annular space of the laboratory borehole model.

TABLE $3 a-$ Results of $t$-tests comparing a neat-cement seal to water backing and air backing in time in the laboratory model.

\begin{tabular}{cccccccc}
\hline \multirow{2}{*}{$\begin{array}{c}\text { Depth, } \\
\mathrm{cm}\end{array}$} & \multicolumn{3}{c}{ Water-Cement, $2 \mathrm{~h}$} & & \multicolumn{3}{c}{ Air-Cement, $2 \mathrm{~h}$} \\
\cline { 8 - 9 } \cline { 7 - 8 } & $t$ & $t_{\text {cr }}$ & Seal? & & $t$ & $t_{\text {cr }}$ & Seal? \\
\hline 2 & 3.59 & 2.09 & Yes & 6.21 & 2.09 & Yes \\
4 & 4.36 & 2.09 & Yes & 6.55 & 2.09 & Yes \\
6 & 4.09 & 2.09 & Yes & 6.43 & 2.09 & Yes \\
8 & 3.08 & 2.09 & Yes & 5.98 & 2.09 & Yes \\
10 & 3.43 & 2.09 & Yes & 6.14 & 2.09 & Yes \\
12 & 4.77 & 2.09 & Yes & 6.73 & 2.09 & Yes \\
14 & 4.70 & 2.09 & Yes & 6.70 & 2.09 & Yes \\
16 & 2.38 & 2.09 & Yes & 5.67 & 2.09 & Yes \\
18 & 3.61 & 2.09 & Yes & 6.22 & 2.09 & Yes \\
20 & 4.29 & 2.09 & Yes & 6.52 & 2.09 & Yes \\
22 & 4.34 & 2.09 & Yes & 6.54 & 2.09 & Yes \\
24 & 4.54 & 2.09 & Yes & 6.63 & 2.09 & Yes \\
26 & 3.21 & 2.09 & Yes & 6.04 & 2.09 & Yes \\
28 & 2.97 & 2.09 & Yes & 5.93 & 2.09 & Yes \\
30 & 3.99 & 2.09 & Yes & 6.38 & 2.09 & Yes \\
32 & 4.08 & 2.09 & Yes & 6.43 & 2.09 & Yes \\
34 & 4.63 & 2.09 & Yes & 6.67 & 2.09 & Yes \\
36 & 4.39 & 2.09 & Yes & 6.56 & 2.09 & Yes \\
38 & 4.02 & 2.09 & Yes & 6.40 & 2.09 & Yes \\
40 & 4.08 & 2.09 & Yes & 6.43 & 2.09 & Yes \\
\hline
\end{tabular}


TABLE $3 b-$ Results of t-tested comparing a neat-cement seal to water backing and air backing in time in the laboratory model.

\begin{tabular}{|c|c|c|c|c|c|c|}
\hline \multirow{2}{*}{$\begin{array}{c}\text { Depth, } \\
\text { cm }\end{array}$} & \multicolumn{3}{|c|}{ Water-Cement, 1 Day } & \multicolumn{3}{|c|}{ Air-Cement, 1 Day } \\
\hline & $t$ & $t_{c r}$ & Seal? & $t$ & $t_{c r}$ & Seal? \\
\hline 2 & -0.18 & 2.09 & No & 4.54 & 2.09 & Yes \\
\hline 4 & -3.54 & 2.09 & No & 3.04 & 2.09 & Yes \\
\hline 6 & -3.29 & 2.09 & No & 3.16 & 2.09 & Yes \\
\hline 8 & -1.20 & 2.09 & No & 4.08 & 2.09 & Yes \\
\hline 10 & 6.01 & 2.09 & Yes & 7.28 & 2.09 & Yes \\
\hline 12 & 2.81 & 2.09 & Yes & 5.86 & 2.09 & Yes \\
\hline 14 & 3.81 & 2.09 & Yes & 6.31 & 2.09 & No \\
\hline 16 & 3.68 & 2.09 & Yes & 6.25 & 2.09 & Yes \\
\hline 18 & 2.82 & 2.09 & Yes & 5.87 & 2.09 & Yes \\
\hline 20 & 2.09 & 2.09 & Yes & 5.54 & 2.09 & Yes \\
\hline 22 & 4.58 & 2.09 & Yes & 6.65 & 2.09 & Yes \\
\hline 24 & 2.37 & 2.09 & Yes & 5.67 & 2.09 & Yes \\
\hline 26 & -3.32 & 2.09 & No & 3.14 & 2.09 & Yes \\
\hline 28 & -6.14 & 2.09 & Yes & 1.89 & 2.09 & No \\
\hline 30 & -2.35 & 2.09 & No & 3.57 & 2.09 & Yes \\
\hline 32 & -1.68 & 2.09 & No & 3.87 & 2.09 & Yes \\
\hline 34 & -3.64 & 2.09 & No & 3.00 & 2.09 & Yes \\
\hline 36 & -1.33 & 2.09 & No & 4.03 & 2.09 & Yes \\
\hline 38 & -1.44 & 2.09 & No & 3.98 & 2.09 & Yes \\
\hline 40 & 0.61 & 2.09 & No & 4.88 & 2.09 & Yes \\
\hline
\end{tabular}

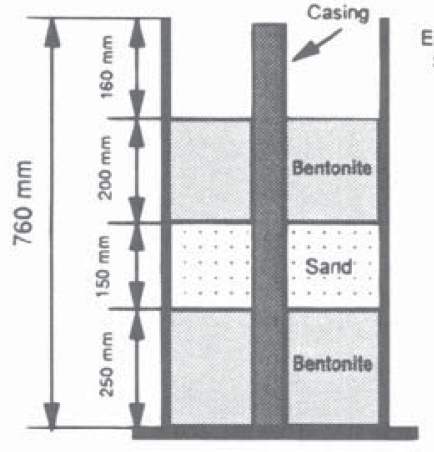

(a)

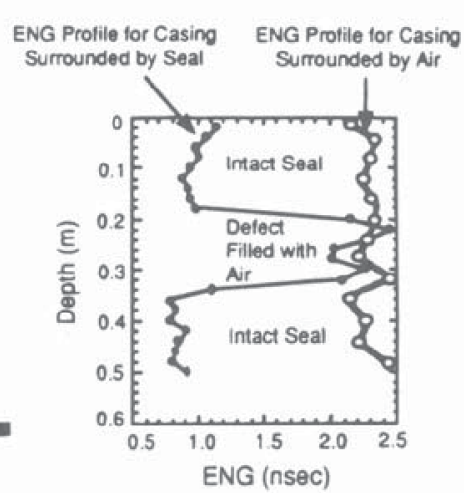

(b)

FIG. 11-Results of tests on bentonite specimen with a single defect. 
TABLE $3 c-$ Results of $t$-tested comparing a neat-cement seal to water backing and air backing in time in the laboratory model.

\begin{tabular}{|c|c|c|c|c|c|c|}
\hline \multirow{2}{*}{$\begin{array}{c}\text { Depth, } \\
\text { cm }\end{array}$} & \multicolumn{3}{|c|}{ Water-Cement, 3 Days } & \multicolumn{3}{|c|}{ Air-Cement, 3 Days } \\
\hline & $t$ & $t_{c r}$ & Seal? & $t$ & $t_{c r}$ & Seal? \\
\hline 2 & -11.37 & 2.09 & Yes & -0.43 & 2.09 & No \\
\hline 4 & -9.61 & 2.09 & Yes & 0.35 & 2.09 & No \\
\hline 6 & -11.29 & 2.09 & Yes & -0.40 & 2.09 & No \\
\hline 8 & -10.92 & 2.09 & Yes & -0.23 & 2.09 & No \\
\hline 10 & -10.43 & 2.09 & Yes & -0.02 & 2.09 & No \\
\hline 12 & -6.68 & 2.09 & Yes & 1.65 & 2.09 & No \\
\hline 14 & -8.59 & 2.09 & Yes & 0.80 & 2.09 & No \\
\hline 16 & -5.89 & 2.09 & Yes & 2.00 & 2.09 & No \\
\hline 18 & -8.59 & 2.09 & Yes & 0.80 & 2.09 & No \\
\hline 20 & -10.39 & 2.09 & Yes & 0.003 & 2.09 & No \\
\hline 22 & -9.65 & 2.09 & Yes & 0.33 & 2.09 & No \\
\hline 24 & -8.88 & 2.09 & Yes & 0.67 & 2.09 & No \\
\hline 26 & -11.33 & 2.09 & Yes & -0.42 & 2.09 & No \\
\hline 28 & -8.57 & 2.09 & Yes & 0.81 & 2.09 & No \\
\hline 30 & -8.90 & 2.09 & Yes & 0.66 & 2.09 & No \\
\hline 32 & -10.29 & 2.09 & Yes & 0.04 & 2.09 & No \\
\hline 34 & -10.65 & 2.09 & Yes & -0.11 & 2.09 & No \\
\hline 36 & -10.94 & 2.09 & Yes & -0.24 & 2.09 & No \\
\hline 38 & -9.57 & 2.09 & Yes & 0.37 & 2.09 & No \\
\hline 40 & -9.82 & 2.09 & Yes & 0.25 & 2.09 & No \\
\hline
\end{tabular}

TABLE 4-Results of t-tests comparing a bentonite seal with a single defect to air backing in the laboratory model.

\begin{tabular}{cccc}
\hline \multirow{2}{*}{$\begin{array}{c}\text { Depth, } \\
\mathrm{cm}\end{array}$} & \multicolumn{3}{c}{ Air (Dry Sand)-Ben Seal } \\
\cline { 2 - 4 } & \multicolumn{1}{c}{$t$} & $\boldsymbol{t}_{\text {cr }}$ & Seal? \\
\hline 2 & 4.42 & 2.06 & Yes \\
4 & 4.72 & 2.06 & Yes \\
6 & 5.05 & 2.06 & Yes \\
8 & 4.93 & 2.06 & Yes \\
10 & 5.18 & 2.06 & Yes \\
12 & 5.40 & 2.06 & Yes \\
14 & 5.25 & 2.06 & Yes \\
16 & 5.23 & 2.06 & Yes \\
18 & 5.03 & 2.06 & Yes \\
20 & 0.76 & 2.06 & No \\
22 & -0.34 & 2.06 & No \\
24 & 0.21 & 2.06 & No \\
26 & 1.19 & 2.06 & No \\
28 & 1.28 & 2.06 & No \\
30 & 0.35 & 2.06 & No \\
32 & 0.96 & 2.06 & No \\
34 & 4.59 & 2.06 & Yes \\
36 & 5.80 & 2.06 & Yes \\
38 & 5.63 & 2.06 & Yes \\
40 & 5.75 & 2.06 & Yes \\
42 & 5.33 & 2.06 & Yes \\
44 & 5.55 & 2.06 & Yes \\
46 & 5.64 & 2.06 & Yes \\
48 & 5.70 & 2.06 & Yes \\
50 & 5.20 & 2.06 & Yes \\
\hline
\end{tabular}




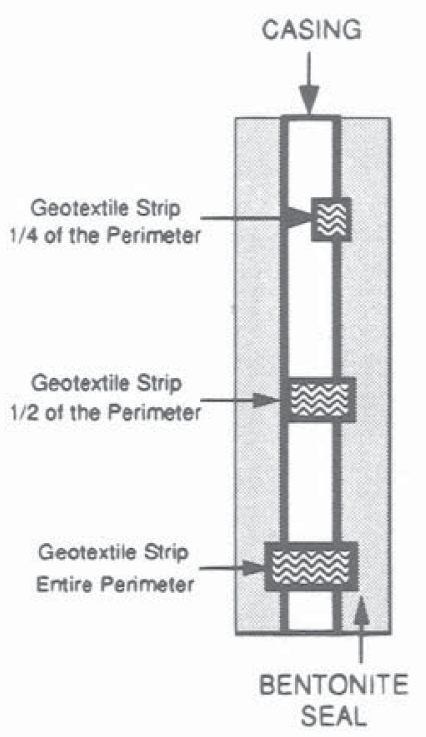

(a)

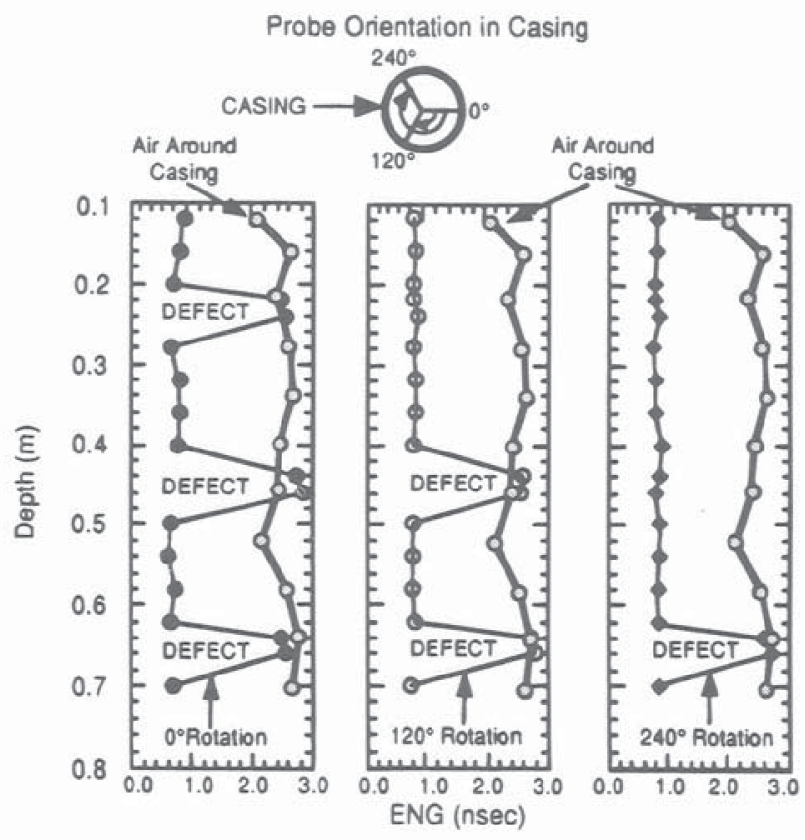

(b)

FIG. 12-Results of tests on bentonite specimen with multiple defects.

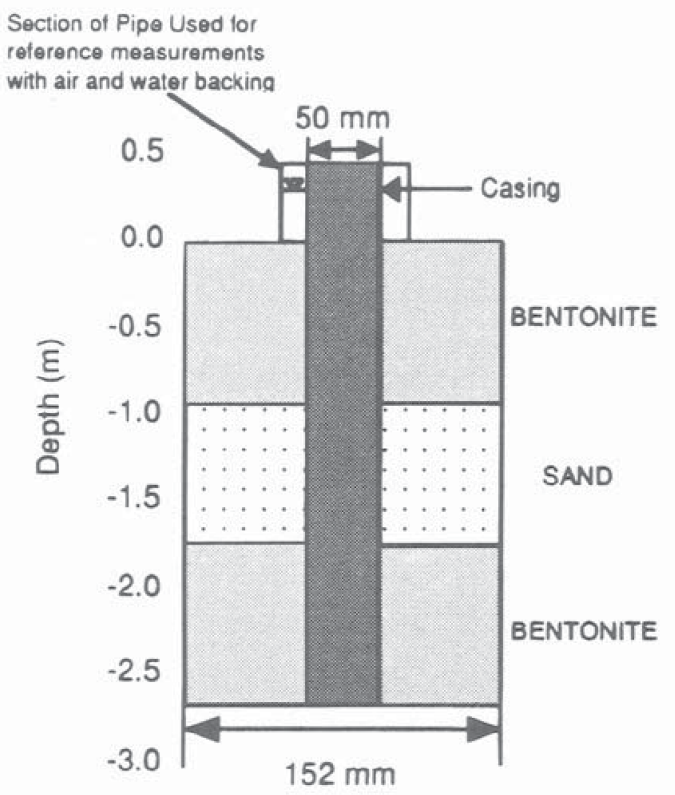

(a)

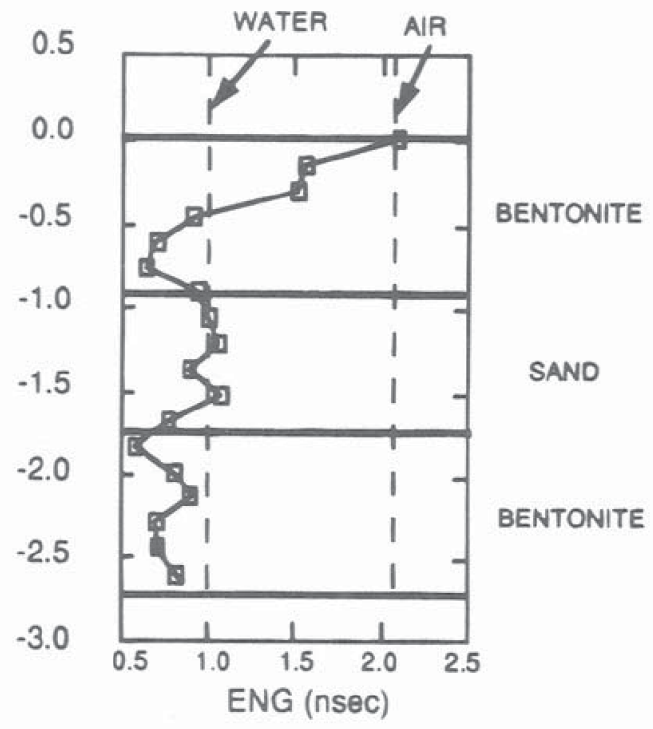

(b)

FIG. 13-Results of field test with bentonite and sand in the annular space. 